\title{
Retinal vein occlusions: The potential impact of a dysregulation of the retinal veins
}

\author{
Stephan A. Fraenkl • Maneli Mozaffarieh • \\ Josef Flammer
}

Received: 21 March 2010 / Accepted: 19 May 2010 /Published online: 18 June 2010

(C) European Association for Predictive, Preventive and Personalised Medicine 2010

\begin{abstract}
A retinal vein occlusion (RVO) is a sight threatening disease. It can be divided into central vein occlusion and branch retinal vein occlusion. The pathogenesis of the condition remains to be solved. Mechanical compression of the vessel wall or thrombotic occlusion of the vessel lumen, sometimes combined with rheological disorders, are often assumed pathomechanisms. Accordingly, the therapy relies either on mechanical decompression, lyses of thrombi or improvement of rheology. A number of observations however, such as the relationship of RVO to atherosclerotic risk factors, spontaneous reversibility particularly in young patients, rest flow observed in angiography, occlusion despite anticoagulation or thrombocytopenia and finally the positive effect of anti-VEGF therapy are not explained by the present pathogenetic concept. As a new concept we propose a local venous constriction induced by vasoconstrictive molecules diffusing from neighbouring diseased arteries and/or from other neighbouring (hypoxic) tissues. Recognizing these postulated conditions might lead to an earlier identification of impending vein occlusions as well as to a treatment more tailored to the risk factor constellation of the particular patient.
\end{abstract}

Keywords Retinal vein occlusion · BRVO .

Personalized treatment $\cdot$ Prevention .

Vascular dysregulation · Endothelin-1

S. A. Fraenkl $\cdot$ M. Mozaffarieh $\cdot$ J. Flammer $(\bowtie)$

Department of Ophthalmology, University of Basel,

Mittlere Strasse 91,

4031 Basel, Switzerland

e-mail: jflammer@uhbs.ch

\section{Introduction}

The German ophthalmologist Leber observed and described the clinical picture of Retinal Vein Occlusion (RVO) [1] about 150 years ago. RVO is the second most common retinal vascular disorder often leading to severe loss of visual function. Roughly, RVOs has been classified as follows: The central retinal vein occlusion, the hemicentral retinal vein occlusion and the branch retinal vein occlusion (BRVO) [2], the latter being the most common type. Although the mechanisms involved might be basically similar in all these types, we shall focus here on BRVOs.

Until today, various pathogenetic mechanisms have been described. Nevertheless, they all leave a number of questions open.

The purpose of this paper is to summarize these unanswered questions and to formulate a new hypothetic concept considering these facts.

\section{Present pathogenetic concepts}

Mechanical compression of the vein

One of the first factors observed by Leber was both, the local relationship of BRVOs to arteriovenous $\mathrm{A} / \mathrm{V}$ crossings and the association with atherosclerosis. It was assumed that the vein is compressed by the rigid artery [3]. It was hypothesized that the over-crossed vein had no space to escape the pressure of the thickened and atherosclerotic altered artery and is compressed or that the vein becomes curved under the pressure of the artery. Both would lead to a disturbed blood flow and to a thrombosis. A common adventitia could fortify this effect $[4,5]$. The concept of mechanical compression is supported by the observation that in case of BRVO, the 
artery crosses more often anterior rather than posterior to the vein [6-8].

Indeed, in patients with atherosclerosis and systemic hypertension, a narrowing of the vein at the $\mathrm{A} / \mathrm{V}$ crossing and signs of turbulence of the blood flow are also visible in fluorescence angiographies [9]. Further, multiple crossings or loops as potential causes of an occlusion have been described [10]. The association of glaucoma with RVOs [11] supports an IOP induced mechanical compression of the vein.

Finally, the so called sheathotomy is also based on the idea of a mechanical compression and indeed, beneficial effects have been described in some studies [12-14].

Sick vein

A proliferation and swelling of the endothelium as well as a subintimal fibrosis has been described [15, 16]. A trophic alteration of the vessel wall with disruption of the blood flow followed by secondary thrombosis of the vessel lumen was postulated.

Other authors however failed to find any pathological altered veins [17].

\section{Hemorheological alterations}

The following parameters have been described in literature to occur more often in RVO compared to controls: Anticoagulant proteins, activated protein $\mathrm{C}$ resistance, factor $\mathrm{V}$ Leiden mutation, antiphospholipid antibodies, anticardiolipin antibodies, platelet aggregation disorders, hyperhomocysteinemia, high plasma viscosity and others [18]. Again, they have been discussed controversially.

It is unknown whether such factors can induce RVOs by themselves or if they are rather cofactors.

\section{Open questions challenging the present concepts}

The pathomechanisms described above raise some questions that are listed below:

1) If we assume the mechanical compression of the vein being important:

Why is a BRVO sometimes reversible [19]?

Why do BRVOs not always occur at A/V crossings [19]?

Why is a distinct vein compression histologically not always visible [20]?

Why do we only extremely rarely find a thrombus $[4,21,22]$ ? And if a thrombus is present why do we find it rather downstream of $\mathrm{A} / \mathrm{V}$ crossings [23]? And if we assume that a thrombus is present, why is the flow not completely interrupted in fluorescence angiographies after BRVO?

Why is the capillary blood flow reduced in areas not affected from BRVO [24]?

Why does BRVOs occur also in younger patients without any signs of atherosclerosis [25]?

Why can we find elevated endothelin levels even in young patients with BRVO [26-28]?

Why does emotional stress seem to be sometime a trigger factor for the development of BRVO [25]?

2) If we consider a sick vein being a major cause:

Why do we find a risk factor constellation similar to arterial diseases such as systemic hypertension, diabetes mellitus, older age, dyslipidemia and smoking but unlike venous diseases [29-32]?

Why does the accompanying retinal edema [33] respond to VEGF inhibitors [34] when the edema is believed to be due to back pressure?

Why is the association between systemic venous thrombotic diseases and RVO extremely low? The prevalence of venous disease in patients with BRVO is approximately $3 \%$ [35].

Why do we, as mentioned before, only seldom find a thrombus in RVOs?

3) If we consider a thrombus formation to be induced by hemorheological alterations and/or alterations to the coagulation cascade:

Why can BRVOs develop in patients with thrombocytopenia or under anticoagulation [18, 36, 37]? Why are only thrombophilic factors associated with RVOs, which are risk factors for both venous thrombosis and arterial vascular disease (in other parts of the body)? Risk factors for venous thrombosis alone seem not to be important [38].

\section{The concept of functional dysregulation of the vein}

We propose a venous dysregulation to be the major component for the development of RVOs. Such a dysregulation implies both inadequate vasoconstriction and increased vessel permeability. The latter, results from an impaired blood-retinal barrier.

Before we discuss this new concept, we shall describe some of the basic mechanisms for vascular regulation and dysregulation:

Like elsewhere in the body the retinal arteries and veins are highly regulated. In general the regulation of arteries has attracted more attention [39, 40], although 
veins are also highly regulated [41]. Among many factors involved, two factors are of special interest in this context: Endothelin-1 (ET-1) for vasoconstriction [42] and the vascular endothelial growth factor (VEGF) for vessel permeability [43].

The vasoactive substances are either produced locally by the endothelial cells and by the surrounding tissue or diffuse from the circulating blood to the smooth muscle cells or pericytes. The influence of these molecules depends upon the function of the bloodretinal barrier. The close relationship between artery and vein at the $\mathrm{A} / \mathrm{V}$ crossing (Fig. 1a and b) facilitates the diffusion of vasoactive substances from the arterial wall directly to the vein.

Under normal conditions (Fig. 2), the endothelial cell of the retinal arterioles and venules respectively release a small amount of ET-1 intraluminally and a larger amount abluminally influencing the local vascular tone. Due to the size of the molecule (21 amino acid peptide) and due to the biological half-life time (around $15 \mathrm{~min}$ ), ET-1 acts mainly locally.
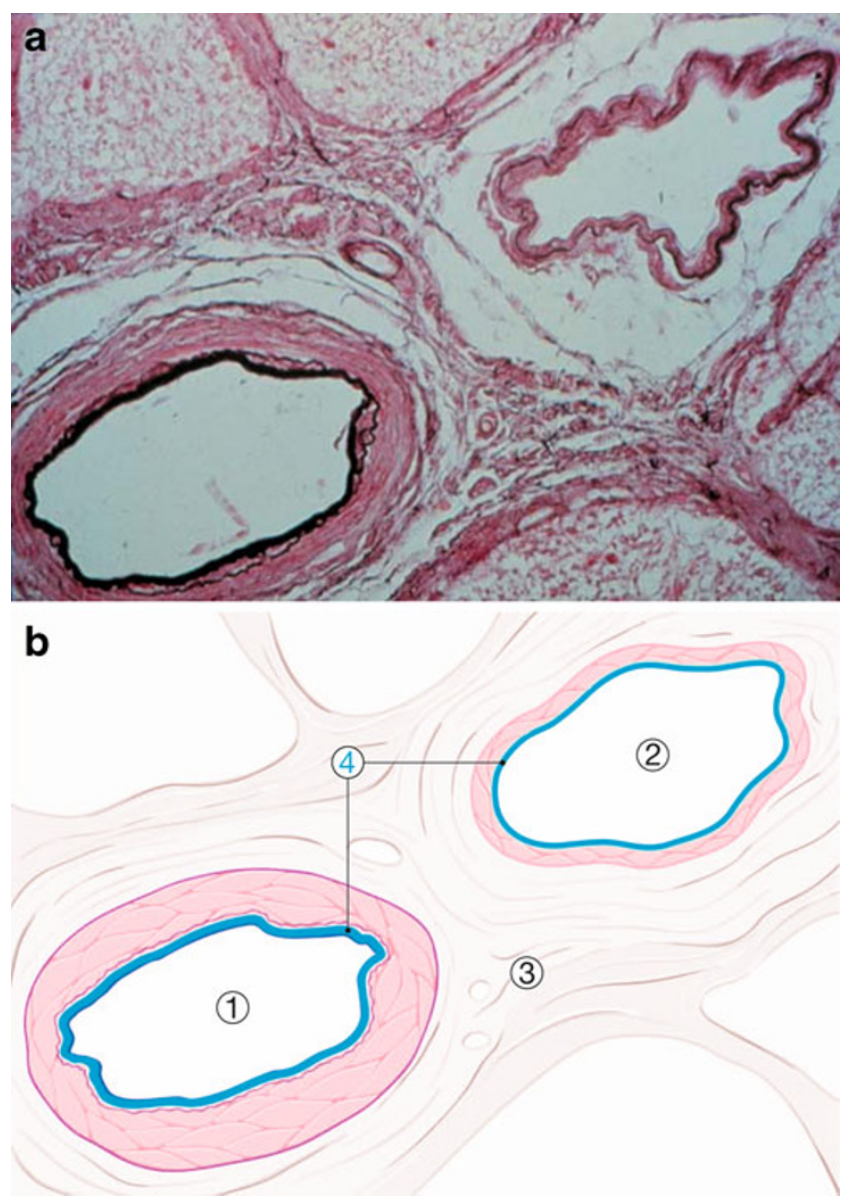

Fig. 1 a Histological cut through an arterio-venous crossing in a human retina. b Schematic drawing. 1. Artery, 2. Vein, 3. Adventitia, 4. Vascular endothelial cell layer (blue)

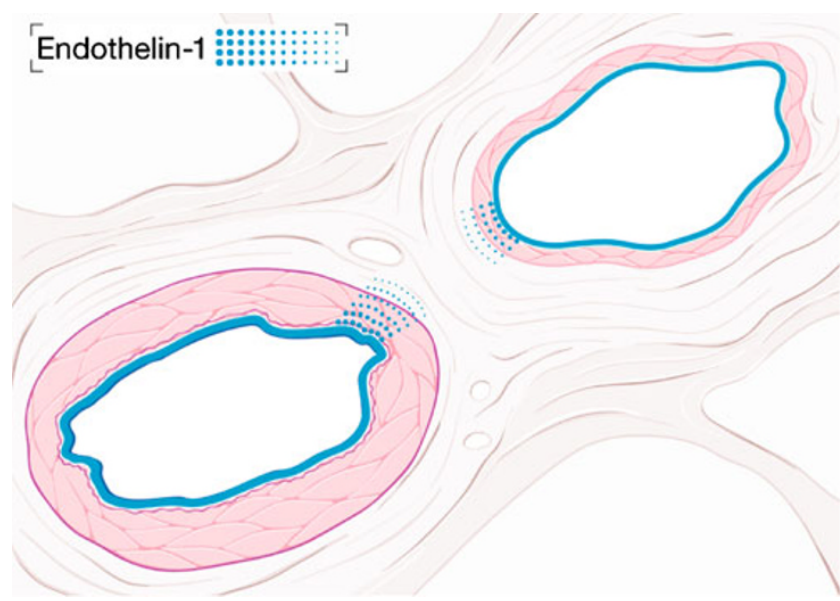

Fig. 2 Physiological condition: Endothelin-1 is produced by the endothelium of the artery and the vein. This affects mainly the underlying smooth muscle cells

In (mostly younger) patients with primary vascular dysregulation (PVD) [44] (Fig. 3), the arterial wall produces (at least under certain circumstances) an increased amount of ET-1. This increases both the ET1 concentration in the circulating blood [45] as well as the ET- 1 concentration in the surrounding tissue of the artery. In extreme situations, particularly if the artery lies back to back to the vein as in $\mathrm{A} / \mathrm{V}$ crossings, this may lead to a local vasoconstriction of the vein.

Such an assumption is supported by the fact that an obstruction of retinal vessels has been shown in animals by endothelin injections in the posterior chamber [46].

In atherosclerosis (Fig. 4), the endothelial cells of the arteries synthesize more ET-1 than healthy normal vessels [47]. In addition, cells of the surroundings of

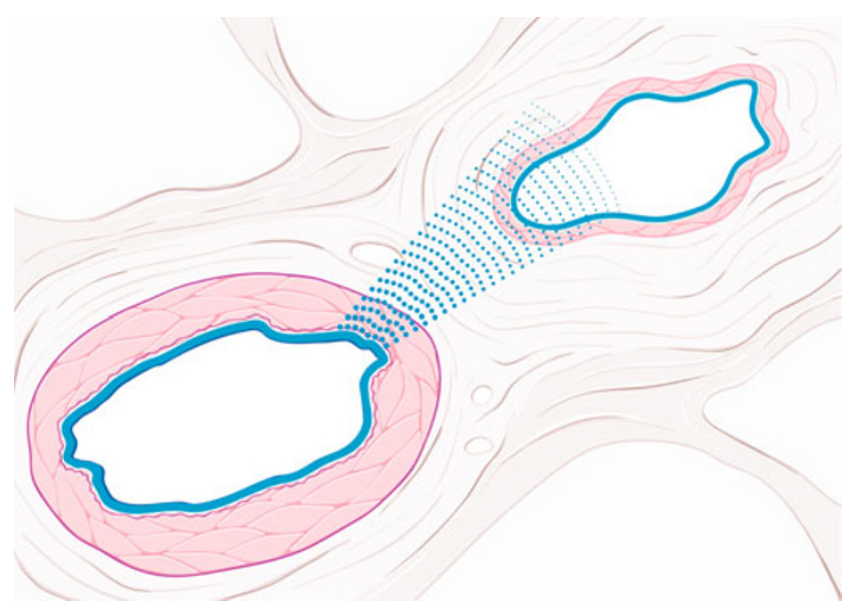

Fig. 3 Vascular dysregulation: The endothelial cells of the artery produce more Endothelin-1 than normal. The vein gets under the influence of this messenger and reacts with a vasoconstriction 


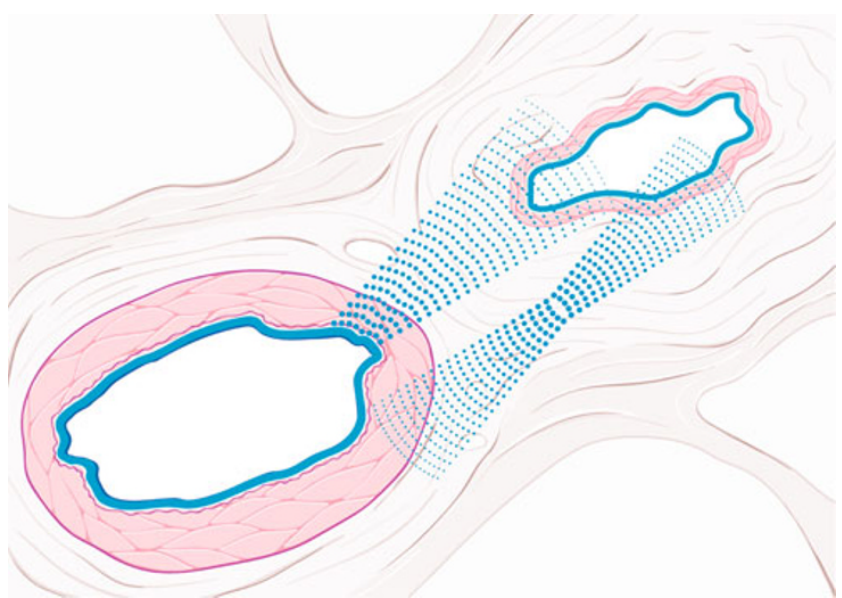

Fig. 4 Atherosclerosis: Due to alterations to the arterial wall and its adventitia, Endothelin-1 is not only overexpressed in endothelial cells but also additionally produced by the cells of the adventitia and by other cells of the surroundings of the atherosclerotic arteries. As consequence, the vein constricts and in extreme situation a RVO results

atherosclerotic arteries and cells of the vessel adventitia also produce ET-1 [48]. Both lead to an increased ET-1 concentration in the neighbouring tissue. This may lead to some constriction of the arteries but even more of the adjacent veins. Veins respond at lower concentrations to vasoconstrictive molecules than arteries [41]. And in addition ET-1 stimulates arterial wall fibrosis further contributing to a narrowing of the vein. The blood-retinal barrier is weekend by several messengers such as ET-1 or VEGF (Fig. 5) [49]. Both, ET-1 and VEGF, are upregulated in hypoxic tissues $[50,51]$ as it is the case in atherosclerosis [52] through a hypoxia inducible factor- $1 \alpha$ (HIF-1 $\alpha$ ) driven cascade (see Fig. 6). These upregulations indirectly point toward a hypoxia caused by arterial dysfunction.

\section{The concept of a functional dysregulation of the vein} gives answers to the following questions

Why is a BRVO often reversible?

Because the vein occlusion has a major functional component: The resulting venous vasoconstriction might fade, for example due to a decrease of the concentration of local constricting factors. If the vessel relaxes RVO resolves partially.

Why do BRVOs not always occur at A/V crossings?

Because veins might come under the influence of vasoconstricting messengers produced by the artery and adventitia independent of an $\mathrm{A} / \mathrm{V}$ crossing in areas where arteries and veins are close enough. And in fact, in these cases the occlusion occurred at a point where the artery and the vein were adjacent [53].

Why is a distinct vein compression histologically not always visible?

The mechanical vein compression might just be a cofactor in addition to the vasoconstriction described above, sometimes present, sometimes not.

Why do we only extremely rarely find a thrombus?

Because the vein occlusion may be due to a functional narrowing of the vein and a thrombus may be absent or if present it might have been developed rather secondary.
Fig. 5 Hypoxic condition: a Hypoxic tissue produces messengers such as VEGF leading to impairment of tight junctions and thereby weakening of the blood-retinal barrier. This leads to increased permeability of the vessels with the development of exudates, retinal edema and leakage in the fluorescence angiography. b Obviously other factors are involved as well. For example MMP-9 can digest the basal membrane which, together with a weakened blood-retinal barrier, even allows erythrocytes to escape the lumen of the vessel

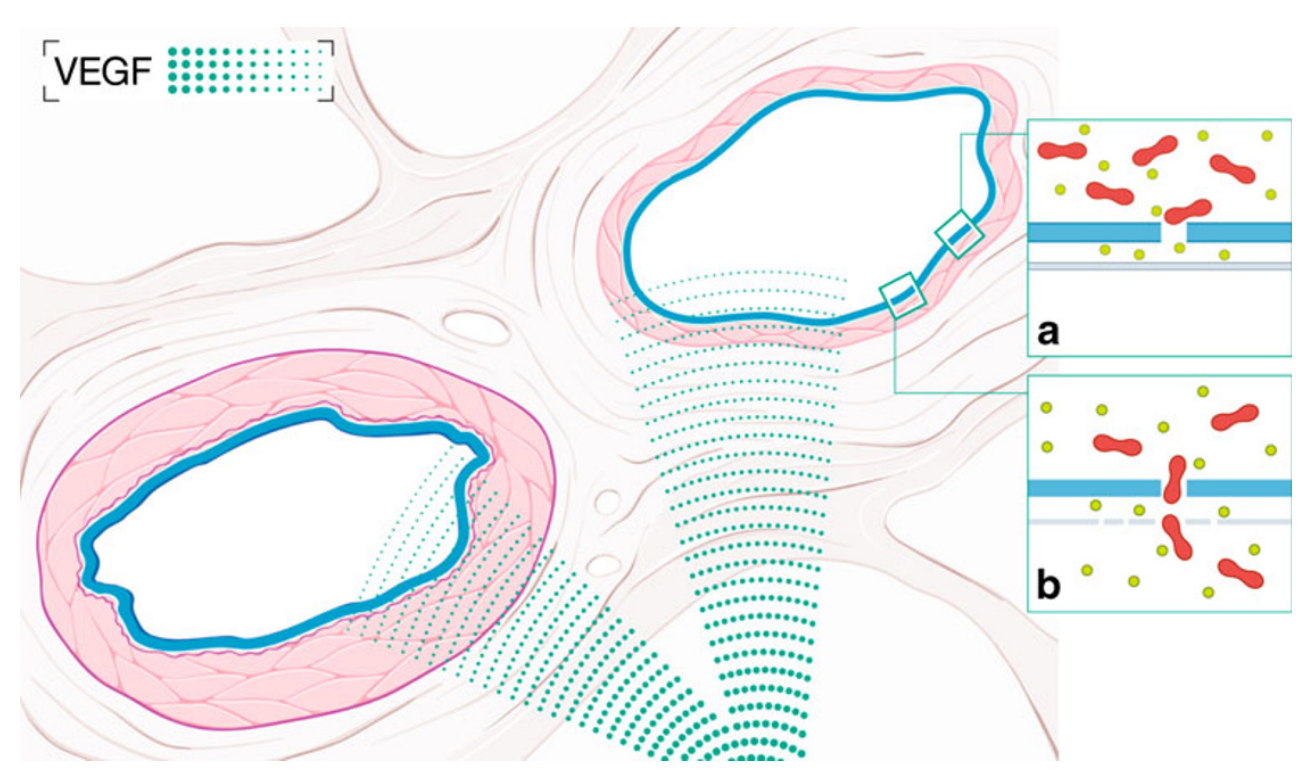


Fig. 6 Induction of hypoxia induced messengers: Hypoxiainducible factor- $1 \alpha(\mathrm{HIF}-1 \alpha)$ is constitutively produced. In situations with a normal $\mathrm{O}_{2}$ concentration in the tissue, HIF- $1 \alpha$ is hydroxylated, ubiquitinated and degraded by the proteosome. In case of hypoxia however, HIF$1 \alpha$ is less hydroxylated and reaches the nucleus where it promotes the expression of other factors such as VEGF, Erythropoietin or ET-1

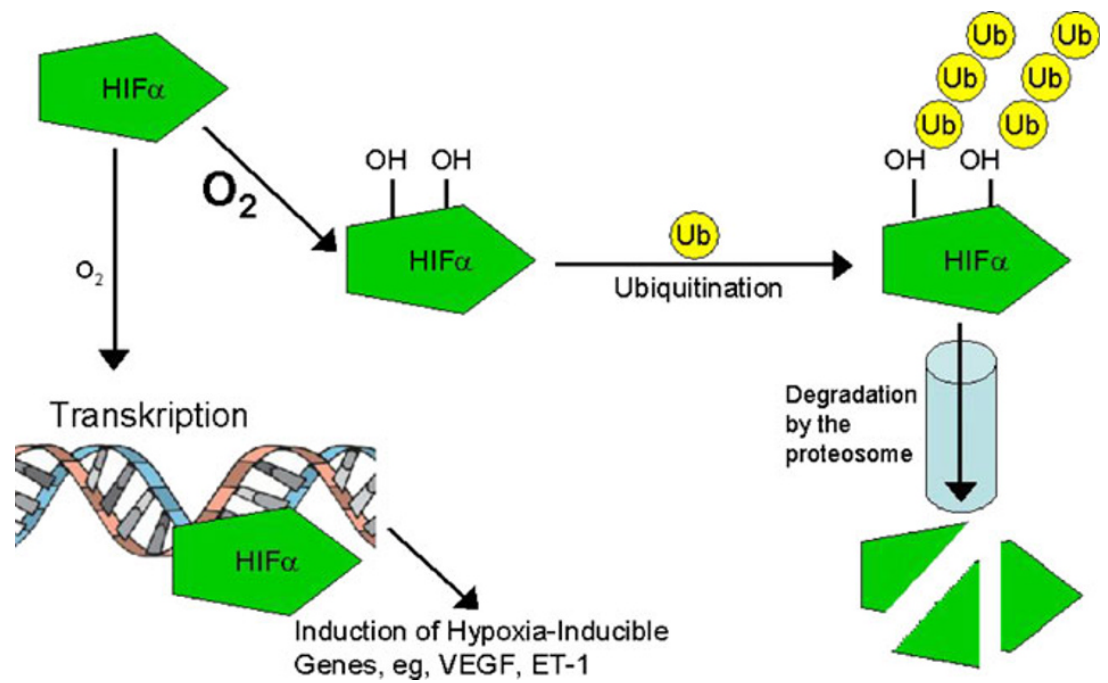

And if a thrombus is present why do we find it rather downstream of $\mathrm{A} / \mathrm{V}$ crossings?

Because the thrombus formation is secondary to the functional narrowing of the vein due to hemodynamic alterations downstream to the narrowing.

And if we assume that a thrombus is present, why is the flow not completely interrupted in fluorescence angiographies after BRVO?

Because the local obstacle to blood flow is rather a venous constriction than a thrombosis. Such a constriction rarely leads to a total occlusion.

Why is the capillary blood flow reduced in areas not affected from BRVO?

Why does the blood flow often remain decreased after the recovery from a BRVO in the area of the former BRVO but also in areas that are not affected and even in the fellow eye?

We assume the primary pathology being on the arterial side leading more or less to hypoxia and upregulation of certain vasoconstrictive messengers. If the concentration of vasoactive factors normalize, the underlying arterial disease (e.g. atherosclerosis) is still present.

Why does BRVOs occur also in younger patients without any signs of atherosclerosis?

Why can we find elevated endothelin levels even in young patients with BRVO?

Why does emotional stress seem to be sometime a trigger factor for the development of BRVO?

In patients with PVD, we find a higher basal ET-1 concentration in the blood than in healthy non-PVD subjects [45]. They often have systemic hypotension [54].
As blood pressure drops, the ET-1 sensitivity increases in subjects with PVD but not so in nonPVD subjects [55].

ET-1 levels increase more in these subjects in situations of emotional stress [56].

In young patients where other risk factors such as atherosclerosis are absent, it is probably a pure functional vasoconstriction triggering the cascade leading to the clinical picture of RVOs.

Why do we find a risk factor constellation similar to arterial diseases such as systemic hypertension, diabetes mellitus, older age, dyslipidemia and smoking but unlike venous diseases?

Because the risk factors for atherosclerosis lead to altered arteries. The endothelial cells of these arteries and the hypoxic surrounding tissues produce an increased amount of local vasoconstrictors.

Why does the accompanying retinal edema respond to VEGF inhibitors when the edema is believed to be due to back pressure?

As a consequence of hypoxia in RVOs, several factors such as VEGF might be upregulated. VEGF is known to cause an impairment of the blood- retinal barrier.

As a consequence retinal edema is treatable with VEGF inhibitors.

Why is the association between systemic venous thrombotic disease and RVO extremely low?

Because a thrombus might be absent and if present it might be due to the narrowing of the vein and rarely a primary event.

If we assume a thrombus, why can BRVOs develop in patients with thrombocytopenia or under anticoagulation? 
Because a thrombus formation might not be necessary for the development of RVOs. A temporal interruption of the blood flow due to a functional narrowing of the vessel might be sufficient for the development of the clinical picture of RVO.

Why are only thrombophilic factors associated with RVOs, which are risk factors for both venous thrombosis and arterial vascular disease (in other parts of the body)? Risk factors for venous thrombosis alone seem not to be important?

Because we postulate a cascade driven by ischemic tissues with a primary pathology of the arteries that secondary influences the vein. An altered arterial vessel wall as well as an hypoxic surrounding tissue might be responsible for an enhanced local endothelin production.

Does the success of sheathotomy indicate mechanical compression?

After surgical separation of the artery from the vein, the vein is separated from the artery at a larger distance and is therefore less influenced by the local messengers. In addition, vitrectomy reduces the retinal hypoxia [57] and thereby reduces the production of vasoactive molecules in the surrounding tissue.

Why is RVO and glaucoma often associated?

RVO occurs more often in glaucoma patients. This can be explained by the fact that RVOs and glaucoma have some risk factors in common leading to the assumption that the two diseases may be interconnected [58]. The corresponding risk factors however seem more pronounced in RVO than in glaucoma:

On the molecular biological level, both in glaucoma as well as in RVOs, substances such as HIF-1 $\alpha$ [59], ET-1 [27] [60], VEGF [33, 61, 62] or Erythropoietin [63, 64] are increased.

On the more physical level, the upregulated substances may lead to both a vasoconstriction [65] and a weakening of the blood-retinal barrier [66]. In glaucoma the factors mentioned above diffuse from the fenestrated choroid to the optic nerve head $(\mathrm{ONH})$. Therefore, vasoconstriction occurs particularly in the peripapillar region $[65,67,68]$. The impaired bloodretinal barrier is visible as increased leakage of the $\mathrm{ONH}$ in fluorescence angiography [66] or in extreme cases even as splinter hemorrhages [69, 70].

The venous pressure is increased in both conditions. This can be observed by an increased ophthalmodynamometric force required inducing venous pulsation and the fewer appearance of spontaneous venous pulsations in glaucoma [71] and RVOs [72].

On the level of aetiology, in both diseases risk factors such as an increased IOP, primary vascular dysregulation [73] and sleep apnea [74, 75] seem to play a role. Interestingly, increased levels of ET-1 have been found in patients with PVD and sleep apnea as well as in animal models with elevated IOP [45, 76-78].

All these factors together sufficiently explain the relationship between glaucoma and RVO.

\section{Conclusion}

About one decade ago, we described primary vascular dysregulation (PVD) as a risk factor for glaucomatous damage. In the present paper we describe a dysregulation of the vein as a component for the pathogenesis of retinal vein occlusions.

While the pathophysiological concepts of RVOs described in the literature so far, cover some aspects of the disease, they are not totally sufficient to explain all phenomena and aspects. Our concept is based on the assumption that we are dealing less with a primary structural pathology of the vein but rather with a functional constriction of the vein. This, in turn, may be secondary due to a change of the arterial vessel wall and/or due to the hypoxic surrounding tissue. Hypoxia induces the upregulation of factors that constrict veins. They may also contribute to the impairment of the blood-retinal barrier leading to oedema and in extreme cases even to hemorrhages.

This concept also explains the relation between RVOs and other diseases including atherosclerosis, glaucoma and PVD.

Further studies are needed to confirm or reject this new concept.

\section{Outlook}

In order to prevent vein occlusions we try to predict such an event with the help of biomarkers. In the present manuscript we describe the vascular dysregulation as a major risk factor and biomarker for vein occlusions. Vascular dysregulation can be recognized based on patient's history (e.g. often cold hands and feet), on clinical examinations (e.g. reduced neurovascular coupling) or laboratory findings (e.g. altered gene expression in lymphocytes).

While we are still in an early stage in search of the relationship between vascular dysregulation and vein occlusions, more information is already available about the relationship between vascular dysregulation and glaucoma [79-81]. The identification of vascular dysregulation in glaucoma patients leads already to a more personalized 
therapy: Glaucoma patients with vascular dysregulation benefit e.g. from an antivasospastic therapy such as calcium channel blockers [82] in addition to the standard intraocular pressure lowering therapy.

A better understanding of the pathophysiology of RVOs and more specific biomarkers related to the individual risk will bring a personalized therapy within reach.

\section{References}

1. von Leber T. Die Krankheiten der Netzhaut und des Sehnerven. In: Handbuch der gesamten Augenheilkunde. Leipzig: GraefeSaemisch; 1877. p. 531.

2. Hayreh SS. Prevalent misconceptions about acute retinal vascular occlusive disorders. Prog Retin Eye Res. 2005;24:493-519.

3. Ennema MC, Zeeman WP. Venous occlusions in the retina. Ophthalmologica. 1953;126:329-47.

4. Koyanagi Y. Die pathologische Anatomie und Pathogenese des Kreuzungsphänomens der Netzhautgefäße bei Hochdruck. Graefes Arch Clin Exp Ophthalmol. 1935;135:526-36.

5. Zhao J, Sastry SM, Sperduto RD, Chew EY, Remaley NA. Arteriovenous crossing patterns in branch retinal vein occlusion. The Eye Disease Case-Control Study Group. Ophthalmology. 1993;100:423-8.

6. Duker JS, Brown GC. Anterior location of the crossing artery in branch retinal vein obstruction. Arch Ophthalmol. 1989;107:9981000.

7. Staurenghi G, Lonati C, Aschero M, Orzalesi N. Arteriovenous crossing as a risk factor in branch retinal vein occlusion. Am J Ophthalmol. 1994;117:211-3.

8. Weinberg D, Dodwell DG, Fern SA. Anatomy of arteriovenous crossings in branch retinal vein occlusion. Am J Ophthalmol. 1990;109:298-302.

9. Christoffersen NL, Larsen M. Pathophysiology and hemodynamics of branch retinal vein occlusion. Ophthalmology. 1999;106:2054-62.

10. Klien BA. Prevention of retinal venous occlusion with special reference to ambulatory dicumarol therapy. Am J Ophthalmol. 1950;33:175-84. illust.

11. Sperduto RD, Hiller R, Chew E, Seigel D, Blair N, Burton TC, et al. Risk factors for hemiretinal vein occlusion: comparison with risk factors for central and branch retinal vein occlusion: the eye disease case-control study. Ophthalmology. 1998;105:765-71.

12. Avci R, Inan UU, Kaderli B. Evaluation of arteriovenous crossing sheathotomy for decompression of branch retinal vein occlusion. Eye. 2008;22:120-7.

13. Kube T, Feltgen N, Pache M, Herrmann J, Hansen LL. Angiographic findings in arteriovenous dissection (sheathotomy) for decompression of branch retinal vein occlusion. Graefes Arch Clin Exp Ophthalmol. 2005;243:334-8.

14. Kumagai K, Furukawa M, Ogino N, Uemura A, Larson E. Longterm outcomes of vitrectomy with or without arteriovenous sheathotomy in branch retinal vein occlusion. Retina. 2007;27:49-54.

15. Frangieh GT, Green WR, Barraquer-Somers E, Finkelstein D. Histopathologic study of nine branch retinal vein occlusions. Arch Ophthalmol. 1982;100:1132-40.

16. Seitz R. The retinal blood vessels. Comparative ophthalmoscopic and histological studies on the healthy and pathologically changed eye. Büch Augenarzt. 1962;40:1-175.
17. Rabinowicz IM, Litman S, Michaelson IC. Branch venous thrombosis-a pathological report. Trans Ophthalmol Soc UK. 1969;88:191-210.

18. Hayreh SS, Zimmerman MB, Podhajsky P. Hematologic abnormalities associated with various types of retinal vein occlusion. Graefes Arch Clin Exp Ophthalmol. 2002;240:180-96.

19. Baglivo E, Dosso A, Pournaras C. Thrombus and branch retinal vein occlusion. Graefes Arch Clin Exp Ophthalmol. 1997;235:10-3.

20. Jefferies P, Clemett R, Day T. An anatomical study of retinal arteriovenous crossings and their role in the pathogenesis of retinal branch vein occlusions. Aust $\mathrm{N} \mathrm{Z} \mathrm{J} \mathrm{Ophthalmol.}$ $1993 ; 21: 213-7$.

21. Greenwood A. Thrombosis of the central retinal vein and its branches. J Am Med Assoc. 1924;82:92-100.

22. Koyanagi Y. Veränderungen an der Netzhaut bei Hochdruck. Path Anat 15 Int Kogr Ophthalmol. 1937;1:143-283.

23. Kumar B, Yu DY, Morgan WH, Barry CJ, Constable IJ, McAllister IL. The distribution of angioarchitectural changes within the vicinity of the arteriovenous crossing in branch retinal vein occlusion. Ophthalmology. 1998;105:424-7.

24. Noma H, Funatsu H, Sakata K, Harino S, Mimura T, Hori S. Macular microcirculation in hypertensive patients with and without branch retinal vein occlusion. Acta Ophthalmol. 2009;87:638-42.

25. Messerli J, Flammer J. Central vein thrombosis in younger patients. Klin Monatsbl Augenheilkd. 1996;208:303-5.

26. Haufschild T, Prunte C, Messerli J, Flammer J. Increased endothelin-1 plasma level in young adults with retinal vascular occlusive diseases. Klin Monatsbl Augenheilkd. 2004;221:357-9.

27. Hollo G. Plasma endothelial-1 concentrations in patients with retinal vein occlusions. Br J Ophthalmol. 1999;83:127-8.

28. Iannaccone A, Letizia C, Pazzaglia S, Vingolo EM, Clemente G, Pannarale MR. Plasma endothelin-1 concentrations in patients with retinal vein occlusions. Br J Ophthalmol. 1998;82:498-503.

29. Cheung N, Klein R, Wang JJ, Cotch MF, Islam AF, Klein BE, et al. Traditional and novel cardiovascular risk factors for retinal vein occlusion: the multiethnic study of atherosclerosis. Investig Ophthalmol Vis Sci. 2008;49:4297-302.

30. Klein R, Klein BE, Moss SE, Meuer SM. The epidemiology of retinal vein occlusion: the Beaver Dam Eye Study. Trans Am Ophthalmol Soc. 2000;98:133-41. discussion 141-133.

31. Mitchell P, Smith W, Chang A. Prevalence and associations of retinal vein occlusion in Australia. The Blue Mountains Eye Study. Arch Ophthalmol. 1996;114:1243-7.

32. Orth DH, Patz A. Retinal branch vein occlusion. Surv Ophthalmol. 1978;22:357-76.

33. Noma H, Funatsu H, Yamasaki M, Tsukamoto H, Mimura T, Sone $\mathrm{T}$, et al. Pathogenesis of macular edema with branch retinal vein occlusion and intraocular levels of vascular endothelial growth factor and interleukin-6. Am J Ophthalmol. 2005;140:256-61.

34. Badala F. The treatment of branch retinal vein occlusion with bevacizumab. Curr Opin Ophthalmol. 2008;19:234-8.

35. Hayreh SS, Zimmerman B, McCarthy MJ, Podhajsky P. Systemic diseases associated with various types of retinal vein occlusion. Am J Ophthalmol. 2001;131:61-77.

36. Browning DJ, Fraser CM. Retinal vein occlusions in patients taking warfarin. Ophthalmology. 2004;111:1196-200.

37. Ducos de Lahitte G, Quintyn JC, Leparmentier A, Mathis A. Retinal vein occlusions in patients treated with anticoagulant and/ or platelet aggregation inhibitors. Five case studies. J Fr Ophtalmol. 2007;30:145-9.

38. Janssen MC, den Heijer M, Cruysberg JR, Wollersheim H, Bredie SJ. Retinal vein occlusion: a form of venous thrombosis or a complication of atherosclerosis? A meta-analysis of thrombophilic factors. Thromb Haemost. 2005;93:1021-6.

39. Ludmer PL, Selwyn AP, Shook TL, Wayne RR, Mudge GH, Alexander RW, et al. Paradoxical vasoconstriction induced by 
acetylcholine in atherosclerotic coronary arteries. N Engl J Med. 1986;315:1046-51.

40. Swedberg KB. Impact of neuroendocrine activation on coronary artery disease. Am J Cardiol. 1998;82:8H-14H.

41. Pellanda N, Flammer J, Haefliger IO. L-NAME- and U 46619induced contractions in isolated porcine ciliary arteries versus vortex veins. Klin Monatsbl Augenheilkd. 2001;218:366-9.

42. MacCumber MW, Jampel HD, Snyder SH. Ocular effects of the endothelins. Abundant peptides in the eye. Arch Ophthalmol. 1991;109:705-9.

43. Connolly DT. Vascular permeability factor: a unique regulator of blood vessel function. J Cell Biochem. 1991;47:219-23.

44. Flammer J, Pache M, Resink T. Vasospasm, its role in the pathogenesis of diseases with particular reference to the eye. Prog Retin Eye Res. 2001;20:319-49.

45. Teuchner B, Orgul S, Ulmer H, Haufschild T, Flammer J. Reduced thirst in patients with a vasospastic syndrome. Acta Ophthalmol Scand. 2004;82:738-40.

46. Takei K, Sato T, Nonoyama T, Miyauchi T, Goto K, Hommura S. A new model of transient complete obstruction of retinal vessels induced by endothelin-1 injection into the posterior vitreous body in rabbits. Graefes Arch Clin Exp Ophthalmol. 1993;231:476-81.

47. Lerman A, Edwards BS, Hallett JW, Heublein DM, Sandberg SM, Burnett Jr JC. Circulating and tissue endothelin immunoreactivity in advanced atherosclerosis. N Engl J Med. 1991;325:997-1001.

48. An SJ, Boyd R, Zhu M, Chapman A, Pimentel DR, Wang HD. NADPH oxidase mediates angiotensin II-induced endothelin-1 expression in vascular adventitial fibroblasts. Cardiovasc Res. 2007;75:702-9.

49. Adamis AP, Miller JW, Bernal MT, D'Amico DJ, Folkman J, Yeo TK, et al. Increased vascular endothelial growth factor levels in the vitreous of eyes with proliferative diabetic retinopathy. Am J Ophthalmol. 1994;118:445-50.

50. Kaur C, Foulds WS, Ling EA. Blood-retinal barrier in hypoxic ischaemic conditions: basic concepts, clinical features and management. Prog Retin Eye Res. 2008;27:622-47.

51. Penn JS, Madan A, Caldwell RB, Bartoli M, Caldwell RW, Hartnett ME. Vascular endothelial growth factor in eye disease. Prog Retin Eye Res. 2008;27:331-71.

52. Faller DV. Endothelial cell responses to hypoxic stress. Clin Exp Pharmacol Physiol. 1999;26:74-84.

53. Clemett RS. Retinal branch vein occlusion. Changes at the site of obstruction. Br J Ophthalmol. 1974;58:548-54.

54. Orgul S, Kaiser HJ, Flammer J, Gasser P. Systemic blood pressure and capillary blood-cell velocity in glaucoma patients: a preliminary study. Eur J Ophthalmol. 1995;5:88-91.

55. Gass A, Flammer J, Linder L, Romerio SC, Gasser P, Haefeli WE. Inverse correlation between endothelin-1-induced peripheral microvascular vasoconstriction and blood pressure in glaucoma patients. Graefes Arch Clin Exp Ophthalmol. 1997;235:634-8.

56. Ergul A, Portik-Dobos V, Giulumian AD, Molero MM, Fuchs LC. Stress upregulates arterial matrix metalloproteinase expression and activity via endothelin A receptor activation. Am J Physiol Heart Circ Physiol. 2003;285:H2225-2232.

57. Stefansson E, Novack RL, Hatchell DL. Vitrectomy prevents retinal hypoxia in branch retinal vein occlusion. Investig Ophthalmol Vis Sci. 1990;31:284-9.

58. Sonnsjo B. Similarities between disc haemorrhages and thromboses of the retinal veins. Int Ophthalmol. 1992;16:235-8.

59. Tezel G, Wax MB. Hypoxia-inducible factor 1alpha in the glaucomatous retina and optic nerve head. Arch Ophthalmol. 2004;122:1348-56.

60. Kaiser HJ, Flammer J, Wenk M, Luscher T. Endothelin-1 plasma levels in normal-tension glaucoma: abnormal response to postural changes. Graefes Arch Clin Exp Ophthalmol. 1995;233:484-8.
61. Lip PL, Felmeden DC, Blann AD, Matheou N, Thakur S, Cunliffe IA, et al. Plasma vascular endothelial growth factor, soluble VEGF receptor FLT-1, and von Willebrand factor in glaucoma. $\mathrm{Br}$ J Ophthalmol. 2002;86:1299-302.

62. Park SP, Ahn JK. Changes of aqueous vascular endothelial growth factor and pigment epithelium-derived factor following intravitreal bevacizumab for macular oedema secondary to branch retinal vein occlusion. Clin Experiment Ophthalmol. 2009;37:490-5.

63. Cumurcu T, Bulut Y, Demir HD, Yenisehirli G. Aqueous humor erythropoietin levels in patients with primary open-angle glaucoma. J Glaucoma. 2007;16:645-8.

64. Garci-Arumi J, Fonollosa A, Macia C, Hernandez C, MartinezCastillo V, Boixadera A, et al. Vitreous levels of erythropoietin in patients with macular oedema secondary to retinal vein occlusions: a comparative study with diabetic macular oedema. Eye. 2009;23:1066-71.

65. Rader J, Feuer WJ, Anderson DR. Peripapillary vasoconstriction in the glaucomas and the anterior ischemic optic neuropathies. Am J Ophthalmol. 1994;117:72-80.

66. Arend O, Remky A, Plange N, Kaup M, Schwartz B. Fluorescein leakage of the optic disc in glaucomatous optic neuropathy. Graefe's archive for clinical and experimental ophthalmology= Albrecht von Graefes Archiv fur klinische und experimentelle. Ophthalmologie. 2005;243:659-64.

67. Grieshaber MC, Flammer J. Does the blood-brain barrier play a role in Glaucoma? Surv Ophthalmol. 2007;52 Suppl 2:S115-121.

68. Rankin SJ, Drance SM. Peripapillary focal retinal arteriolar narrowing in open angle glaucoma. J Glaucoma. 1996;5:228.

69. Grieshaber MC, Terhorst T, Flammer J. The pathogenesis of optic disc splinter haemorrhages: a new hypothesis. Acta Ophthalmol Scand. 2006;84:62-8.

70. Yoo YC, Park KH. Disc hemorrhages in patients with both normal tension glaucoma and branch retinal vein occlusion in different eyes. Korean J Ophthalmol. 2007;21:222-7.

71. Morgan WH, Hazelton ML, Azar SL, House PH, Yu DY, Cringle $\mathrm{SJ}$, et al. Retinal venous pulsation in glaucoma and glaucoma suspects. Ophthalmology. 2004;111:1489-94.

72. Jonas JB. Ophthalmodynamometric assessment of the central retinal vein collapse pressure in eyes with retinal vein stasis or occlusion. Graefe's archive for clinical and experimental ophthalmology $=$ Albrecht von Graefes Archiv fur klinische und experimentelle. Ophthalmologie. 2003;241:367-70.

73. Flammer J, Haefliger IO, Orgul S, Resink T. Vascular dysregulation: a principal risk factor for glaucomatous damage? J Glaucoma. 1999;8:212-9.

74. Leroux Les Jardins G, Glacet-Bernard A, Lasry S, Housset B, Coscas G, Soubrane G. Retinal vein occlusion and obstructive sleep apnea syndrome. J Fr Ophtalmol. 2009;32:420-4.

75. Mojon DS, Hess CW, Goldblum D, Fleischhauer J, Koerner F, Bassetti C, et al. High prevalence of glaucoma in patients with sleep apnea syndrome. Ophthalmology. 1999;106:100912.

76. Prasanna G, Hulet C, Desai D, Krishnamoorthy RR, Narayan S, Brun AM, et al. Effect of elevated intraocular pressure on endothelin-1 in a rat model of glaucoma. Pharmacol Res. 2005;51:41-50.

77. Saarelainen S, Seppala E, Laasonen K, Hasan J. Circulating endothelin-1 in obstructive sleep apnea. Endothelium. 1997;5:115-8.

78. Weiss JW, Liu MD, Huang J. Physiological basis for a causal relationship of obstructive sleep apnoea to hypertension. Exp Physiol. 2007;92:21-6.

79. Gasser P, Flammer J, Guthauser U, Mahler F. Do vasospasms provoke ocular diseases? Angiology. 1990;41:213-20. 
80. Gugleta K, Zawinka C, Rickenbacher I, Kochkorov A, Katamay $\mathrm{R}$, Flammer J, et al. Analysis of retinal vasodilation after flicker light stimulation in relation to vasospastic propensity. Investig Ophthalmol Vis Sci. 2006;47:4034-41.

81. Mozaffarieh M, Schoetzau A, Sauter M, Grieshaber M, Orgul S, Golubnitschaja $\mathrm{O}$, et al. Comet assay analysis of single-stranded
DNA breaks in circulating leukocytes of glaucoma patients. Mol Vis. 2008;14:1584-8.

82. Koseki N, Araie M, Tomidokoro A, Nagahara M, Hasegawa T, Tamaki Y, et al. A placebo-controlled 3-year study of a calcium blocker on visual field and ocular circulation in glaucoma with low-normal pressure. Ophthalmology. 2008;115:2049-57. 